\title{
FUNCTION AND MECHANISM OF ANGIOTENSIN-CONVERTING ENZYME-2 RECEPTOR TO TRANSPORT SARS-COV-2 INTO THE HOST CELLS-A REVIEW
}

\author{
Muhammad Bilal ${ }^{1}$, Muhammad Sarfaraz Iqbal ${ }^{2}$, Muhammad Husnain Iqbal ${ }^{3}$, Nimra Sardar ${ }^{4}$, \\ Wajiha Akmal ${ }^{4}$, Rabia Sultan ${ }^{5}$, Sarmad Ahmad Qamar ${ }^{6}$
}

\footnotetext{
${ }^{1}$ School of Life Science and Food Engineering, Huaiyin Institute of Technology, Huaian 223003, China.

${ }^{2}$ Department of Biotechnology, School of Applied Biology, University of Okara, Pakistan.

${ }^{3}$ Department of Orthotics and Prosthetics, Government College University Faisalabad, Pakistan.

${ }^{4}$ Department of Molecular Biology, School of Applied Biology, University of Okara, Pakistan.

${ }^{5}$ Department of Microbiology and Molecular Genetics, University of Okara, Pakistan.

${ }^{6}$ Department of Biochemistry, University of Agriculture, Faisalabad, Pakistan.
}

Received - September 15, 2020; Revision - October 14, 2020; Accepted - October 25, 2020

Available Online October 28, 2020

DOI: http://dx.doi.org/10.18006/2020.8(Spl-1-SARS-CoV-2).S190.S201

\section{KEYWORDS \\ SARS-CoV-2 \\ Respiratory disease \\ Angiotensin-converting enzyme 2 receptor \\ Spike protein}

\begin{abstract}
Novel coronavirus disease (COVID-19) caused by severe acute respiratory syndrome coronavirus-2 (SARS-CoV-2) has rapidly spread across the world. SARS-CoV-2 is viewed as a continuous global health threat resulting in an alarming number of fatalities worldwide. Angiotensin-converting enzyme-2 (ACE2) has been recognized as one of the vital receptors for the SARS-CoV-2, leading to viral entry into the host cells. It also helps many other receptors, which initiate the entry of SARS-CoV-2 in the host body. A variety of proteins and enzymes are involved in triggering the transport mechanism. The route of viral infection depends on the distribution and expression of receptors, as the virus reaches the cell by binding to cell receptors to complete intracellular replication, virus release, and cause cytotoxicity. In addition to alveolar lung tissues, ACE2 also plays a pivotal role in other organs. Due to the abundant presence in lung cells, SARS-CoV-2 mostly affects the lungs and causes their destruction. The spike protein utilizes the digestion of ACE2, which strongly contributes to the pathogenesis of severe lung failure. Different experiments show that ACE2 not only helps the virus to migrate in the host cell but also allow us to fight against this pandemic disease. This review article summarizes the current progress that highlights the critical biological functionalities and mechanisms of ACE2 as the novel receptor to transport SARS-CoV-2 into host cells matrix.
\end{abstract}

* Corresponding author

E-mail: bilaluaf@hotmail.com; bilaluaf@hyit.edu.cn (M. Bilal)

Peer review under responsibility of Journal of Experimental Biology and Agricultural Sciences.

Production and Hosting by Horizon Publisher India [HPI] (http://www.horizonpublisherindia.in/).

All rights reserved.
All the articles published by Journal of Experimental Biology and Agricultural Sciences are licensed under a Creative Commons Attribution-NonCommercial 4.0 International License Based on a work at www.jebas.org.

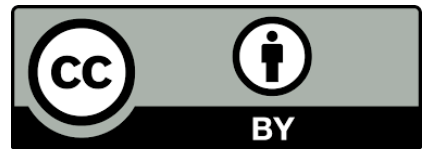




\section{Introduction}

World health organization (WHO) has declared coronavirus disease (COVID-19) a pandemic that has rapidly spread to each country, around the world (WHO, 2020). The pandemic has executed more than 1,181,955 individuals, and about 44,978,190 have been affected. Until now, more than 32 million individuals have been recovered. COVID-19 has influenced about 216 nations and domains and the worldwide means of transportation (Hui et al., 2020). The available information indicates a large number of populations carrying COVID-19 virus around the globe (Hui et al., 2020). During 2003, the major health issue was confirmed as a severe acute respiratory syndrome (SARS) that created a pandemic situation. SARS-CoV was a kind of coronavirus, containing a large portion of positive-chain RNA, which codes for the replication of viral proteins such as spike (S) protein, covering, nucleocapsid, and some non-coding proteins (Buchholz et al., 2004; Bojkova et al., 2020). Phylogenetic studies show that SARS$\mathrm{CoV}$ is denoted among the known examples of antigenic coronavirus (Ramaiah et al., 2018). Another coronavirus (SARS$\mathrm{CoV}$ ) has been viewed as the causative agent of SARS, which causes severe pneumonia (O'Keeffe, 2019). Similarly, Spanish influenza and new respiratory disease have brought high mortality because of high pneumonic disorder (Lai et al., 2020).

In December 2019, another coronavirus initiated pneumonia was found in Wuhan, Hubei Territory of China (MacIntyre, 2020). It is also named 2019-nCoV by WHO, which frames a branch in the subfamily Orthocoronavirinae in the subgenus Sarbecovirus. Despite standard respiratory responses, such as fever, 2019-nCoV has a strong relationship with SARS-CoV with over $85 \%$ characteristics. Only a few infected persons may likewise encounter different indications, for example, shedding inside organs and a liver infection (Lai et al., 2020). ACE2 has been demonstrated as a fundamental receptor for the novel 2019-nCoV because 2019-nCoV is directly linked with SARS-CoV (Li et al., 2007; Lai et al., 2020; Monteil et al. 2020). The infection depends upon the exposure and the distribution of the pathogenic organism (He et al., 2006). Since the specific role of ACE2 and SARS-CoV2 in COVID-19 may have significant consequences for the understanding of the disease, we investigated its role in the pathogenesis of organ damage in COVID-19.

\section{ACE2 receptor and its properties}

ACE2 receptor is down-regulated by SARS-CoV, which is linked explicitly with viral S-protein causing severe pneumonia (Dhama et al., 2020a). The ACE2 receptor contains the M2 N-terminal region of the peptidase and the renal amino-debasing space of the C-terminal region (Wong et al., 2003). ACE2 can be found in numerous organs of the body, and links the cellular matrix of alveolar cells, with little vessel enterocytes in several organs of the pneumonic type II ( $\mathrm{Li}$ et al., 2003). The expression of ACE2 by mRNA is also found in the cerebral cortex. The presence of ACE2 in cortical neurons makes them susceptible to SARS-CoV-2, which is a potential reason for the anosmia and heartbeat issues during COVID-19 (Arumugam et al., 2020). Since anosmia and dysgeusia were at first observed symptoms in different patients with COVID19 , it was proposed to consider them as an indicator of COVID-19 exposure (Letko \& Munster, 2020).

Previously, investigations have been performed to check the immunolocalization of ACE2 in healthy human organs (Hamming et al., 2004). In lung alveolar epithelial cells and small intestinal epithelial cells, ACE2 was highly expressed, consistent with possible routes of SARS-CoV-2 viral transmission, as both respiratory and gastrointestinal systems share external environment interfaces. In all the organs tested, ACE2 was present in vascular endothelial cells and smooth muscle cells. In the kidney, ACE2 was strongly expressed in proximal tubular cells at the brush border and moderately or weakly in parietal epithelial cells and podocytes, while in glomerular endothelial cells and mesangial cells, ACE2 staining was weak or negative. It was also present in the basal epidermal layer of the skin and the oral and nasal mucosa Conversely, no ACE2 was found in lymphoid tissues and hepatobiliary structures (Hamming et al., 2004). RAASindependent ACE2 functions are strongly demonstrated by extreme staining on different epithelial cells (small intestine, kidney, skin). These results cause alternative hypotheses about the participation of ACE2 in the pathways of viral transmission. In summary, ACE2 is widely distributed in human tissues, both in the main SARSCoV-2 target organs and in organs that play an apparently less significant or even unknown role in the pathophysiology of COVID-19 (Hussain et al., 2020).

In cell lines, the involvement of ACE2 was seen as a potential SARS-CoV receptor target (Wong et al., 2003). It is necessary to understand the pathogenesis of SARS-CoV because of the high mortality rate during SARS-CoV infection, the terrible impacts on the economy and society, and the anxiety of economic recovery about potential maltreatment of diseases, for example, organic weapons. The essential distinctive feature is that ACE2 is a basic receptor for SARS-CoV in-vivo. SARS-CoV infection and spike glycoprotein lower ACE2 expression. The SARS-CoV spike combination in mice significantly upgrades in-vivo lung problems that may be adjusted with the aid of debilitating the renin-angiotensin pathway. These consequences provide a subatomic explanation of why SARS-CoV infections are this much lethal and consistent lung difficulty and offer standard treatment for SARS and other respiratory diseases. ACE2 has been considered as the co-receptor of SARS coronavirus in cell lines. In all the cases, the second potential receptor CD209L (LSIGN) was likewise seen during in vitro assessments (Letko \& 
Munster, 2020). Therefore, it is complicated whether ACE2 is significant for in vivo SARS-CoV conditions. ACE2 is a substantial in vivo SARS receptor, which is essential for the correct replication of the inhibitory SARS-CoV-2 infection.

\section{SARS-CoV host entry point}

Like ACE2, full-length proteins lies in the major parts of coronaviruses, e.g.,HCoV, NL63, SARS-CoV (an infection that causes SARS), and SARS-Cov-2 (which cause COVID-19 infections). In the SARS-CoV S1 top protein and SARS-CoV-2 ACE2, functions as a trigger outside the mammalian cells, and transports infection routes within the cell endosomes. This requires the activation of the TMPRSS2 S serine protease protein zone ( $\mathrm{Li}$ et al., 2007). At any stage demonstration of numerous spaces S1, $\mathrm{S} 2$, and planes are given by the coronavirus S-glycoproteins surface S2 (recognized 681-1255). HR1 and HR2 are differen inhibition sites, which can be discovered to frame a collection of six helicases, a positive way to deal with forestall blending of gp41 of HIV and MHVS ( $\mathrm{Li}$ et al., 2003; Li et al., 2007). Beginning the SARS-CoVS-glycoprotein present a more remarkable point that influences the associated proteins (He et al., 2006).

ACE2 has also been shown to be a significant COVID-19 novel receptor since it is closely linked to the SARS-CoV. The route of viral infection depends on the expression and distribution of the corresponding receptor, as the virus reaches the cell by binding to cell receptors to complete intracellular replication, virus release, and cause cytotoxicity (Jayawardena et al., 2019). The damage caused by the virus in various organs, is closely linked to clinical manifestations and has a significant influence in clinical practice on understanding pathogenesis and developing therapeutic strategies. Bioinformatic tools found that ACE2 is highly expressed in renal cells, especially in tubular cells (Jayawardena et al., 2019). Researchers working with mice models showed that the presence of the viral glycol-proteins with ACE2 stimulates a decrease in the degree of ACE2 expression in cells through the presence and the degradation of proteins (Hoffmann et al., 2020a) Rat subjects have indicated that ACE inhibitors and angiotensin II receptor blockers (ARBs), used to treat hypertension, increased the expression of ACE2 and may impact the perfection of coronary diseases. They found that the utilization of ACE inhibitors was related to a $34 \%$ decrease in the risk of pneumonia symptoms. Moreover, the danger of pneumonia was likewise decreased in patients treated with MEA inhibitors, who had an increased risk of pneumonia, especially in patients with stroke and cardiovascular disorders. It has been related to a decrease in pneumonia mortality, by giving little attentionto how to improve the outcomes with reduced chances than those of a general danger of pneumonia. A trial of hospitalized patients in the Chinese hospital of Hubei province found a 3.7\% the disaster in April 2020 (Kanne, 2020).
Hospitalized patients experiencing hypertension who had consumed vasoconstrictor protein inhibitors or vasodilator inhibitors of $9 \%$ for hypertensive patients, who were not taking these medications, suggested that the strategies were impractical against the corona (Wang et al., 2020a). Results from IHC showed no expression of ACE2 in glomerular cells. Renal tubular cells have reabsorption and excretion roles and play a key role in metabolite excretion, body fluid balance maintenance, and acidbase balance (Sanchis-Gomar et al., 2020). Renal tubular cell injury could lead to atrophy of renal tubules, thus worsening renal interstitial fibrosis, secreting into the stroma a variety of chemokines and growth factors, promoting interstitial inflammatory cells infiltration, the proliferation of intrinsic interstitial cells, and accumulation of extracellular matrix. 2019nCoV could also reach the renal tubular cell by binding to ACE2, which causes cytotoxicity and irregular renal function (Tian et al., 2020). To diagnose impaired renal function in time and provide early interventions, the assessment, and follow-up of renal function of patients infected with 2019-nCoV are important. Current clinical statistics indicate that a significant proportion of novel coronavirus (2019-nCoV) infected patients with pneumonia are young adults and even infants. Therefore, as a post-complication, viral testicular damage could occur. The role of ACE2 as the entry point for the transmission of SARS-CoV in-vivo is depicted in Figure 1.

\section{Recombinant human ACE2}

Recombinant human ACE2 (rhACE2) has been described as another targeting point for SARS-CoV-2 for invasive lung injury and seems to improve lung hemodynamics. The half-life of rhACE2 in people is around 10 hours, and the beginning of development is 30 minutes regardless of the period of 24 hours ( $\mathrm{Li}$ et al., 2007). A few studies recommend that rhACE2 could prove a promising target for the individuals who were generally taking RAS inhibitors, or in sicknesses where angiotensin II distribution is high. ACE is one of the enzymes that catalyze the conversion of angiotensin I to angiotensin II. Ang II, the main active RAAS component, exerts its effects mainly via angiotensin-II type 1 receptors (AT1R). ACE2 cleaves Ang II to angiotensin (1-7), which exerts vasodilating, anti-inflammatory, and anti-fibrotic effects through binding to the receptor (Sanchis-Gomar et al., 2020). This also hinders the protective impact of ACE2 on the severity of the syndrome of acute respiratory distress (ARDS). The damaging effects of Ang II, have previously been seen in many ARDS animal models (Kuba et al., 2005; Liu et al., 2020).

There is a high degree of correlation between the interactions between ACE2 and SARS-CoV-1 and SARS-CoV-2, as well as more downstream impacts (Hoffmann et al., 2020a). Ang IIinduced pulmonary vasoconstriction occurs during hypoxia, aimed at restoring ventilation-perfusion mismatch and causing adverse 


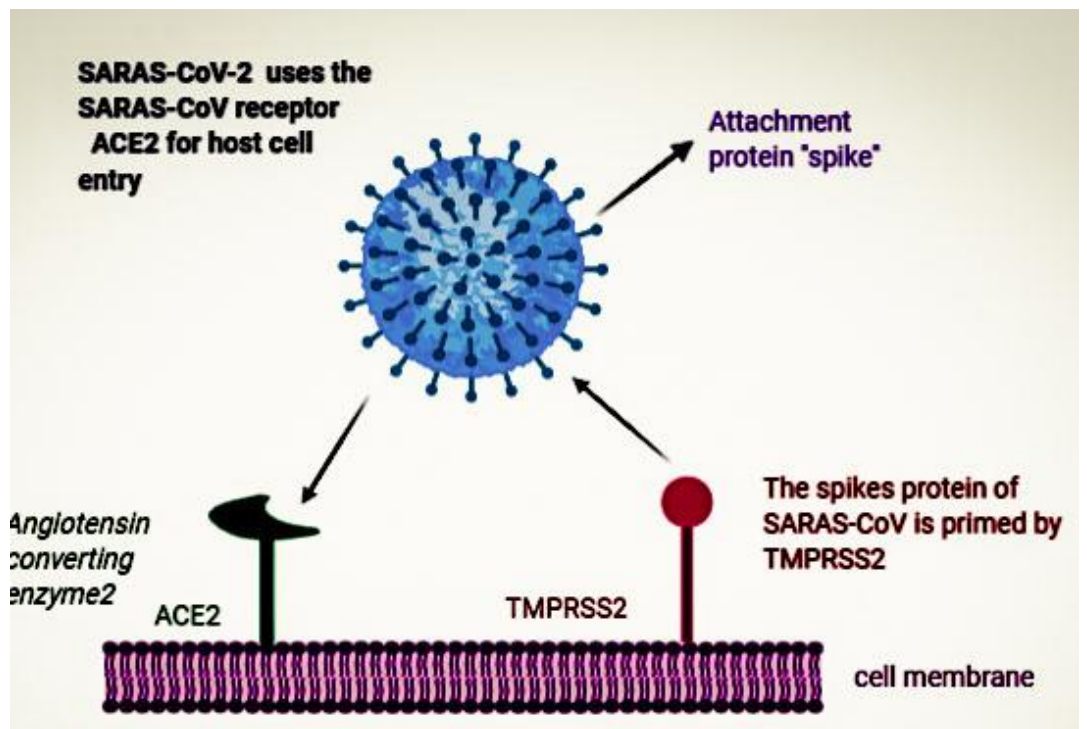

Figure1 ACE2 serves as the entry point for the transmission of SARS-CoV in-vivo.

pro-fibrotic effects, both of which are enhanced by concomitant ACE2 up-regulation (Gaur et al., 2018). SARS-CoV-2 may induce down-regulation of ACE2, under similar circumstances, disrupt the clearance of Ang II and thus lead towards tissue damage. On the other hand, one can speculate that SARS-CoV-2 down-regulation of ACE2 results in a decreased chance of further entry into the viral cells, thus restricting viral spread. Since one would assume that SARS-CoV-2 infects ACE2-expressing cells with greater efficiency compared to SARS-CoV, SARS-CoV-2 viruses will likely need less ACE2 to enable viral distribution, apparently by exploiting cellular factors promoting viral attachment and entry. Taken together, the function of ACE2 is complex and not yet established in SARS-CoV-2 cellular infection, which makes it important to research whether and how SARS-CoV-2 interferes with the expression and control of ACE2 and how this influences viral replication. This may suggest a differential vulnerability across various populations to SARS-CoV-2 infection. However, no evidence supporting potential S-protein binding resistant ACE2 mutants was obtained (Cao et al., 2020a). To analyze changes in ACE2 variants and the intermolecular interactions with the $\mathrm{S}$ protein, structural modelling and superimposition studies of the native ACE2- and ACE2-S-protein complex were used. Most ACE2 coding variants demonstrate high structural similarity and similar binding affinity with the S-protein of SARS-CoV-2. Two allelic variants that exhibited substantial variation in intermolecular interaction with the S-protein were established showing varying spatial orientation of main interacting ACE2 residues (Hussain et al., 2020). These genetic variations in ACE2 can provide the basis for a potential relative or complete resistance to SARS-CoV-2 infection.

\section{SARS-CoV and SARS-CoV-2 supportive proteins}

Mass spectrometric examination indicated a high similarity of 332 proteins between SARS-CoV-2 and human beings. To study viral proteins, we carried qualitative evaluation seeing the significant transportable characteristic strategies of the collaborating proteins, along with lipoprotein metabolism, nuclear vehicle (Nsp7), and biogenesis of ribonucleoprotein (Nsp8) (Pyrc et al., 2004). The observations of the development of DNA polymerase spaces in the interactors of Nsp1 and the improvement of bromodomains and extra-terminal (Bet) circle of families for interactors of $\mathrm{E}$ (van der Hoek et al., 2006). The binders of $\mathrm{E}$ are similar as in the recognition sites uncovered for the potential to acetylated histones. Because of its 10 to 20 times increased binding affinity to ACE2, SARS-CoV-2 is more pathogenic than SARS-CoV (Hoffmann et al., 2020b). In combination with S-protein priming by the host cell protease TMPRSS2, this binding contributes to host cell entry of the virus. SARS-CoV-2 cell entry and pathological effects occur predominantly in (upper) respiratory tract cells (Wang et al., 2020b). The cells used for AP-MS tests, HEK-293T kidney cells, are lenient to SARS-CoV-2 disease, and they do not manage with the central physiological network designed for undermining (Kanne, 2020).

This information explains the theory that SARS-CoV-2 is quite ensured about proteins exposed in lung tissues, and the study of tissue expression may also make more robust the treatment based on host factors with less vital responses. This observation is specifically influencing its confirmation from HEK293 cells, which could also not associate with the lungs (Lai et al., 2020). 
SARS-CoV-2 association chart with those decided for 10 pathogens, seeing WNV and Mycobacterium tuberculosis (Mtb) as having the maximum similar host protein with supplementary devices (Ramaiah et al., 2018). Finally, the influential families of the host-cells proteins, infection described in substitute humans as the central level, which may be protected under observed subnuclear parts. The segregated coverage of the human proteins found within the SARS-CoV-2 interactome, the 332 SARS-CoV-2 giving human proteins had depleted missense, and no longer immaculate prevent changes in genome (Penn et al., 2018).

The most fundamental purpose of ACE2 is to carry the hormone angiotensin I in the angiotensin II vasoconstrictor ( $\mathrm{Li}$ et al., 2007). ACE2 expels the hazardous carboxyterminal amino-phenylalanine from angiotensin II (Asp-Arg-Val-Tyr-Ile-His-Pro-Phe-His-Leu) and hydrolysis in the angiotensin vasodilator (ASP-ARG-VALTYR-ILE-HIS-PRO). It can relatively detach a few unique peptides, including retenequinone, apelin, neurotensin, dynorphin, and ghrelin (Hoffmann et al., 2020b). ACE2 exerts systemic effects on the cardiovascular system on adipocytes, and laboratory studies have shown associations between gender, adipocyte ACE2, and obesity complications, such as hypertension (Gupte et al., 2012). Noticeably, leptin is one of the most significant adipokines that drive these pro-inflammatory effects, and increased availability of leptin has been correlated with increased levels of Ang II and decreased expression and activity of ACE2 (Ibrahim et al., 2014). Besides, elevated levels of leptin have been associated with alveolar fluid accumulation and increased inflammation after hypoxia and ARDS (Bellmeyer et al. 2007). It can therefore be hypothesized that excess visceral adipose tissue in patients with COVID-19 can contribute to the progression of the disease, whether gender-affected or not, especially by worsening the cascade of hyperinflammatory reactions in the disease (van der Voort et al., 2020). Ultimately, this cytokine storm in patients with COVID-19 can lead to multiple organ failure.

The main advantage of the EMC protein of the human coronavirus is transmitted in 293T transfected cells and assembled into retroviral assemblies (Bojkova et al., 2020). Retroviral particles pseudo-typed with S-glycoproteins have been appropriately used to indicate the existence of the coronavirus cells, including SARS$\mathrm{CoV}$. In this manner, the pseudo-typing circumstance can be utilized to consider the cell portion separated from EMC-S. The beneficial expression of viral envelope proteins in transfected cells is a basic component of the pseudo-type. Western blotting of 293T, HeLa, and BHK-21 cells transfected to transmit EMC-S with a Cterminal antigenic unique finger impression uncovered two evident social chances, 170 and $100 \mathrm{kDa}$, and a little band, $60 \mathrm{kDa}$, that were not seen in the heap cells transfected with the unfilled plasmid, showing that protein S was balanced effectively (Penn et al., 2018).
The discovery of two common events is apparent with the cleavage of protein $\mathrm{S}(170 \mathrm{kDa}$ ) in an $\mathrm{N}$-terminal (not distinguished) and $\mathrm{C}$ terminal (100 kDa) subunit by cell proteases (Qamar et al., 2020). To decide whether the valuable expression of EMC-S includes a blend of virions, co-transfection of HIV-1, and EMC-S in 293T cells were analyzed, and the $S$ protein that joins the cells extracted from these cells. SARS-S joined as a positive control, as exhibited that SARS-S joins into retroviral particles (Hoffmann et al., 2020a). Western blotting of pseudo particles released from transfected 293T cells undoubtedly found beneficial for SARS-S particle and protein S, symbolically, was not separated, according to the dissipated data. A similar quality sign was assessed for EMC-S and, indeed, two away from occasions of 170 and $100 \mathrm{kDa}$ were examined, exhibiting that EMC-S and SARS-S combined into retroviral particles with proportional efficiencies and the last $S$ protein is not adequately treated by cell proteases (Luytjes et al., 1987).

In COVID-19 patients with venous and arterial thromboembolism, which is a characteristic of the anti-phospholipid syndrome (APS), strongly increased levels of antiphospholipid (anticardiolipin and anti- $\beta 2$-glycoprotein I) antibodies were recorded (Chen et al., 2020; Zhang et al., 2020). Systemic lupus patients often present with APS and vasculopathy-caused limb ischemia. In a systemic lupus clinical trial, anti-ACE2 antibodies were found to be elevated and associated with the relative activity of serum ACE2 in almost every patient (Takahashi et al., 2010). As a result of hypomethylation, systemic lupus patients overexpress ACE2, and their vascular complications react very well to hydroxychloroquine therapy, with circumstantial evidence of a speculative correlation between ACE2 and COVID-19 vascular complications (Sawalha et al., 2020).

The main advantage of the EMC protein of the human coronavirus interferes with the place in cell lines from different human tissues. Accordingly, pseudo-typed retroviral particles with EMC-S could decide to transduce human cells. Pseudo-types conveying the VSV G protein have been utilized as a positive control since VSV-G improves the transduction of an inconceivable level of cell types (Xiao et al., 2003). For the pseudo-type, a vector encoding luciferase was utilized, and control of transduction was constrained by looking at luciferase repeats in lysates of transduced cells. The pseudo-types transmission VSV-G was established to transduce a wide range of transporters consistently. EMC-Sassisted transduction of Caco-2 (colon), HOS (osteosarcoma), Huh-7 (liver), and MRC5 (lung), while EMC-S transduction SARS-CoV did not ensure RPE (retina), U373 (glioblastoma), and A549 cells (lung). Transduction of 293 and 293T cells (kidneys) was similarly observed; however, a portion of these may clarify the common differences in heretofore darken hCoV-EMC receptor flagging. Many of the currently available studies have been unadjusted for 
possible confounding factors, including factors, such as smoking and diet, including age, sex, and lifestyle. Many experiments were equally unregulated, had relatively short follow-up times, or were possibly impacted by incorrect counting or underdiagnosis (Jordan et al., 2020).

\section{Function of the spike protein in SARS-CoV-2}

A variety of ACE2 has been demonstrated as a functional receptor for the severe disorder of SARS-CoV-2 (Liu et al., 2004). ACE2 is found in endothelial vascular cells. It must be noticed that SARSCoV-2 is pathogenic in the lungs (Qamar et al., 2020). Although ACE2 management in the lungs has been demonstrated to be type I and type II, the tropism of SARS-CoV cells does not coordinate ACE2 guidance, proposing that different parts are expected to decide the pathogenesis of this disease. The order of proteins, for example, trypsin, mini-plasmin, and trypsin-like proteins from the human aviation route (top), and TMPRSS2 (transmembrane proteinase, serine 2), are known to restrict glycine only (Hoffmann et al., 2020b). The breakdown of HA is basic for viral diseases, the correctness of tissue proteins that decide the cell tropism of infectious strains (Ingallinella et al., 2004). There are two fundamental structural conditions liable for the proteolytic stimulation of viral glycoproteins in certain diseases, for example, human immunodeficiency viral infection (HIV) and Nipah contamination, cell proteins (for instance furin or cathepsin) (Janson et al., 2017).
The debasement of viral glycoprotein by endosomal proteases in different infections, for example, Ebola and SARS-CoV cause mechanism changes during the infection area after the original receptor or endocytosis (Marra et al., 2003). Trypsin, cathepsin L, and elastase proposed clarifications for the start of the peak of the SARS-CoV (S) protein. Without proteins on the cell surface, SARS$\mathrm{CoV}$ enters the cells intramuscularly, and protein $\mathrm{S}$ is instigated to be blended with cathepsin L in the endosome (Wong et al., 2003). Infection replication has once demonstrated to be better than intracellular replication in the last case, recommending that the expanded infectivity of SARS-CoV in the lungs might be the immediate effect of the development (Pyrc et al., 2004). The entry of cells facilitated by protease has been described in Figure 2. In this diagram, we considered how TMPRSS2 act as an activator of the SARS-CoV region in the cells. TMPRSS2 is overall transmitted to epithelial cells in the human lungs (Hoffmann et al., 2020a), and initiates flu and post-pneumonic infection in culture cells.

\section{ACE2 and respiratory infections}

Viral pneumonia progresses with progressive ground-glass opacity on chest computed tomography (CT) in more serious cases requiring hospitalization. This is followed by more complications in clinically vital cases, including ARDS, heart pathology, and secondary infections. Given the similarity between SARS-CoV and SARS$\mathrm{CoV}-2$, there is significant equivalence in lung pathology (Wu et al., 2020). Limited records of predominantly autopsy cases have so far

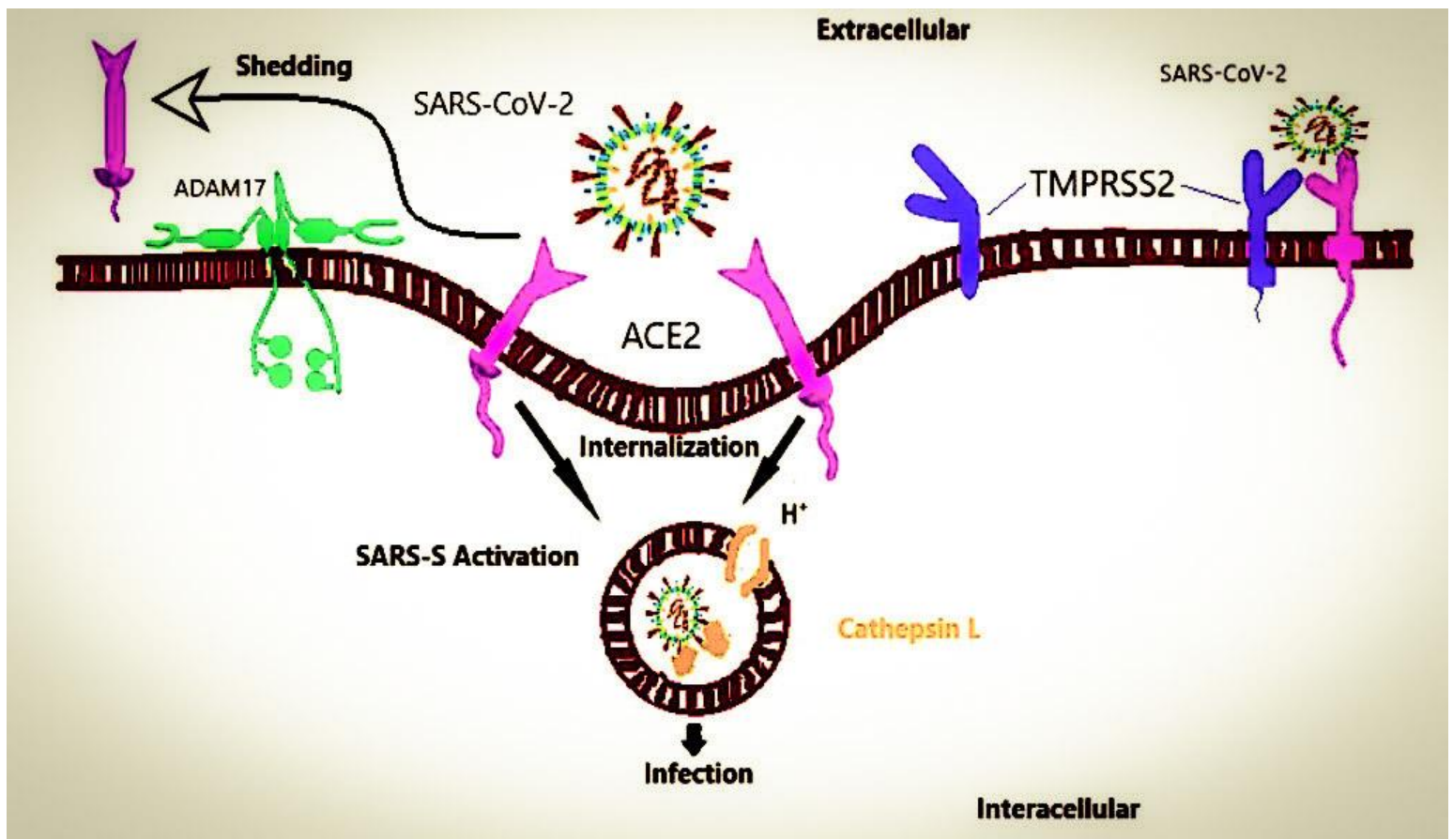

Figure 2 Representation of ACE2 utilization for SARS-CoV-2 to enter cell and the prognosis of infection.

Journal of Experimental Biology and Agricultural Sciences http://www.jebas.org 
identified pathological lung findings (Barton et al., 2020; Tian et al., 2020). In general, COVID-19-associated pathological changes in the lungs, similar to SARS, constitute substantial diffuse alveolar damage with bilateral edema, protein or fibrin alveolar exudates, and diffuse-type II pneumocyte reactive hyperplasia (Xu et al., 2020a; Tian et al., 2020). Like the flu, coronaviruses depend on TMPRSS2 for the infection site and spread to the host (Hoffmann et al., 2020a; Qamar et al., 2020). As a host organism with great attention, the viral haemoglobin protein adds to the adjustment of ACE2, which is encoded by the nature of ACE2 and transmitted to respiratory epithelial cells. Subsequently, haemoglobin is diminished to begin the disease. This outcome relies upon the proteins in the host cell, specifically, on the TMPRSS2 type 2 transmembrane serine protease (Wang et al., 2004).

Furthermore, SARS-CoV-2 and different other kinds of coronary diseases, and flu depend upon the presence of infections and cell entrance in TMPRSS2. SARS-CoV has been connected with danger for the SARS since 2003 (Letko \& Munster, 2020). These models emphasize the principal and appropriate action of TMPRSS2 in the pathogenesis of several kinds of coronary diseases. At the point when assessed in vitro utilizing key cell lines and lung cells, the TMPRSS2 protein inhibitor, a monastic incentive, effectively anticipated the detachment of SARS-CoV-2 in the lung epithelial cells (Babcock et al., 2004). There is more thrombo-embolic pathology found in specimens from patients with COVID-19 compared to SARS. Intra-alveolar deposition of neutrophilic granulocytes, most likely due to superimposed bacterial infection, was also recorded in a few instances. Another case study showed immunostaining of the SARS-CoV-2 Rp3 NP protein, which was prominently expressed both in alveolar epithelial cells and in cell debris within the alveolar space.

In the TMPRSS2 knockout model in mice tainted with H1N1, the underlying change was slight, and there was a weak progression with lung disease, weight reduction, and mortality contrasted. Given its principal use in the beginning periods of SARS-CoV-2 and other respiratory infections, adjustment to the definition or advancement of TMPRSS2 must permit promising alternatives for potential medications against COVID-19 (Qamar et al., 2020). ACE2 has been observed in the respiratory tract in nasal and bronchial epithelial cells. Besides, ACE2 is abundantly expressed on the surface of alveolar type II pneumocytes, which also coexpress several other genes involved in the regulation of viral replication and transmission, including TMPRSS2 (Narasaraju, 2020). Pneumocytes of type II generally produce surfactants, sustain their self-renewal, and perform immunoregulatory functions. With closely applied capillary endothelial cells, these cells share the same basement membrane and express the elevated levels of ACE2 (Keam et al., 2020). This data indicates that along with the associated capillary endothelium, type II pneumocytes may be the primary site of SARS-CoV-2 entry, resulting in damage to those cells and the alveolo-capillary membrane and continued type II pneumocyte reactive hyperplasia. This can lead to a vicious cycle of continuous destruction and repair of the alveolar wall, eventually resulting in progressive extreme diffuse alveolar damage, as type II pneumocytes remain targets of viral entry and replication.

\section{ACE2 expression in human epithelium}

ACE2 is utilized in all cases as a SARS-CoV receptor for entrance into tissues and cells. The expression and activity of ACE2 are ubiquitous within the human body, but many of its factors on the tissue level are unknown. In COVID-19 pathophysiology, there is enormous spatiotemporal heterogeneity in the involvement of organs, possibly because the observed tissue damage can cause multiple pathophysiological mechanisms. The observed pathological findings could be responsible for both SARS-CoV-2 infection, directly mediated by ACE2 expression and activity, and superimposed disease triggers. An immunosuppressive region good with the glycosylated type ACE2 has been identified in human and wastewater from evacuated lung tissue. In all cases, the kind of cells that ACE2 gives was not found in this investigation because endothelial and epithelial cells can transmit ACE2 (Li et al., 2007; Hoffmann et al., 2020b).

As ACE2 is abundantly expressed in the body by endothelial cells, it loses its ability to prevent thrombosis upon SARS-CoV-2 entry into the host cells. ACE2 has been shown to play a role in defence of endothelial function and inhibition of inflammatory response in in-vitro human umbilical vein endothelial cell cultures (Zhang et al., 2015). Putatively, SARS-CoV-2 direct endothelial cell infection could result in systemic impairment of microcirculatory function in various vascular bundles. SARS-CoV-2 has recently been shown to infect human blood vessel organoids directly invitro. SARS-CoV-2 endothelial cell permissiveness in-vivo was demonstrated by electron microscopy in renal glomerular endothelial cells (Varga et al., 2020). However, as no immunohistochemistry or immune electron microscopy has been performed, it has remained challenging to differentiate between intracellular viral inclusions and normal subcellular organelles, as they can masquerade as viruses (Miller \& Brealey, 2020). Also, endothelitis was associated with COVID-19 in various organs such as the lung, liver, heart, kidney, and small intestine (Varga et al., 2020). This suggests that direct endothelium infection and/or perivascular inflammation can lead to endothelial dysfunction, tissue edema, and microvascular pathology resulting in a procoagulant state, particularly in patients with pre-existing endothelial dysfunction. In addition, since COVID-19 patients have normal to slightly elevated platelet levels, strongly elevated fibrinogen levels and normal to only prolonged somewhat prothrombin and activated partial thromboplastin time have been 
observed (Ranucci et al., 2020). As commonly found in sepsis, thromboembolic events in these patients do not tend to arise from hypofibrinolytic ingestion of diffuse intravascular coagulation (Klok et al., 2020).

A sensitive ACE2 signal was also significantly felt in some starter types. ErbB2, the alpha-insulin receptor was powerfully rich on the newfound key side, confirming a particular biotinization bituminization. ACE2 is transmitted to the human aviation route epithelium. ACE2 protein levels were managed to utilize human immunodeficiency evaluation from the human alveolar tissues. To confirm a model to test this hypothesis, SEM was used to analyze the morphology of the upper surface of the entire separated epithelium with that of intensely detached cells. The loss of this basic cell isolation list by revival was related to a significantly decreased expression of mRNA and ACE2 protein. Rather than causing an interesting epithelium, the segregated essential human tracheobronchial epithelium (hTBE) or A549 cells made in plastics for tissue cultures convey little mRNA or ACE2. foxj1, an understanding fixing required for an epithelial phenotype that has been detached all around, has likewise been examined in a planned path with ACE2, showing that ACE2 is significantly connected with epithelial status. Basal tracheobronchial cells made in an incubation culture was moved with an adenoid transporter gave by ACE2, a negative $\beta$-galactosidase, or foxj1 witness (Ramaiah et al., 2018).

\section{Discussion}

ACE2 in human tissues identifies targets, including the lungs and gastric tract. It's an ectoenzyme that changes from angiotensin II to angiotensin. SARS-CoV is spread through respiratory cells and by direct contact with an infected individual. Studies recommend that virus enters the host through the mucous film of the respiratory tract and eyes. Selected information on human diseases is principally acquired from patients with intense respiratory viral infections, including respiratory disorders, which show the symptoms of the disease to the proximal and distal epithelium. The greater part of the human respiratory tissue material from patients with ARVI was acquired regardless fourteen days after the beginning of the disease. The lung tissues of these patients showed changes in diffuse alveoli, scaled epithelial cells, type II cell hyperplasia, fibrin, and collagen in the alveolar space (Hoffmann et al., 2020b).

Although both dendritic cells express non-integrin by getting ICAM3 (DC-SIGN; CD209) and DC-SIGNR (L-SIGN, CD209L), they can examine the SARS-CoV infection of cells that report ACE2. These proteins are not acceptable for causing disease without ACE2 receptor (Takahashi et al., 2010). The utilization of SARS-CoV or pseudo-typed retroviral vectors with SARS S protein has indicated that avian human epithelial cell lines are not adequately transduced, which is a fantastic mechanism that presents issues concerning the outermost ranges of the respiratory epithelium, helping SARS-CoV disease (Dhama et al., 2020b). Since SARS-CoV disease in the epithelial course of aeronautics is an ACE2 arm and endorsement of ACE2 is commonly basic for every single disconnected cell. So, the low transduction proficiency of nonpolarized and inadequately detached cells is not abrupt (Zhang et al., 2015). Disconnection of epithelium improved the transduction of pseudo-typed protein $\mathrm{S}$ virions in some degree subordinate way (Dhama et al., 2020b). With regards to useful tainting of the coordination of the epithelium of the aviation course, apically discharged SARS-CoV can be mitigated by the chance of mucous layers and access to the gastrointestinal tract. SARS-CoV raises the cells of the gastrointestinal tract, and the free digestive tract is a clinical sign regularly found in patients with SARS (Cao et al., 2020b).

This instance of apical diseases and the presence of destruction in epithelium takes place after infection of transmissible porcine gastroenteritis and HCoV-229E (Sievers et al., 2011). It is an exciting fact that murine hepatitis A59 infiltrate cells are charmed by apical surfaces and leave the basolateral side. Tests for the course of epithelial division and cutoff shows that SARS-CoV shuts all cells disengaged from the apical surface and only goes to the apical side. These mechanisms should likewise apply to the NL63 section in the epithelium of human aeronautics (Chiu et al., 2005). The epithelial confirmation of the ACE2 was dynamically related to the detachment of cells and revelation that might be at the core of detachment to infection. The apical clarification of ACE2 on the epithelium shows that this coronavirus is available for topical use by receptor inhibitors. Up until this point, the segments that control the ACE2 application have not been recognized (Matoba et al., 2015). Future inspections of the ACE2 support and revelation of value data identified with cell separation may uncover ACE2 controllers and the event of shortcomings in SARS-CoV and NL63.

Among the fourteen tendencies of the SARS-CoV top protein that depend up on human ACE2 because of the SARS-CoV receptor, 8 amino acids are directed explicitly in the SARS-CoV-2 apex protein homology (Xu et al. 2020b). SARS-CoV-2 makes use of ACE2 receptors to infect individuals, bats, civet, cats, monkeys, and pigs yet no longer mice. Appeared differently concerning as of late enrolled SARS-CoV strains, SARS-CoV-2 makes use of ACE2 receptors more capable of human SARS-CoV; anyway, this is less reasonable than human SARS-CoV (Cao et al., 2020a). Protein exchange chooses two critical traits of SARS-CoV-2: step by step specific ability to defile and increasingly extensive pathogenicity. It seemed that SARS-CoV is just looking like a bat, which decreases pathogenicity diverged from SARS-CoV. The preventing of plague is sizable, but the treatment of COVID-19 is 
unpreventable (Malik et al., 2020). A sizable perception of the essential pathogenic units of SARS-CoV-2 will reveal different objectives for better COVID-19 treatment.

\section{Concluding remarks}

Seven types of $\mathrm{CoV}$ have been recognized that cause human diseases. One out of seven is an exceptionally pathogenic infection, which is SARS-CoV-2. SARS-CoV-2 relates to the upper respiratory tract, although some of them can cause serious infections in infants, youngsters, and the old. Various investigations have been performed to consider the pathogenesis of SARS-CoV protein (S) and N protein present protection from viral particles. Protein $\mathrm{N}$ is an auxiliary protein that takes an interest in virion to get together and assumes a focal role in the proficiency of infection interpretation. Protein S can tie to receptors in sensitive cells and intervene in disease in target cells after, which it starts to reproduce in the cytoplasm. Indeed, the infection stimuli sclerosis, atelectasis, and interleave, which eventually exacerbates breathing troubles. CoV can enter cells through the connection of the $\mathrm{CoV} S$ protein and its host receptor, ACE2, which is disconnected from VeroE6 cells satisfactory for SARS-CoV. ACE2 has been distinguished as a key ligand buildup and functional receptor for SARS-CoV-2 and may likewise ensure alveolar cells. Downregulation of ACE2 prompts over the top creation of angiotensin II through a protein connected to pro and incitement of the angiotensin II receptor type 1A (AGTR1A) that can produce expanded pneumonic vascular penetrability. This may clarify the expansion in lung grimness during ACE2 articulation. White blood cells transfected with ACE2 structure a multinucleated syncytium with cells communicating protein $\mathrm{S}$. Antibodies against ACE2 can cause Streptococcus pneumonia infection replication in Vero-E6 cells.

\section{Acknowledgments}

All listed author(s) are thankful to their representative universities/institutes for providing the related support to compile this work

\section{Conflict of interest}

The listed author(s) declare no conflict of interest in any capacity, including competing or financial.

\section{References}

Arumugam VA, Thangavelu S, Fathah Z (2020) COVID-19 and the World with Co-Morbidities of Heart Disease, Hypertension and Diabetes. Journal of Pure and Applied Microbiology 14: 1623-1638.

Babcock GJ, Esshaki DJ, Thomas WD, Ambrosino DM (2004) Amino acids 270 to 510 of the severe acute respiratory syndrome coronavirus spike protein are required for interaction with the receptor. Journal of Virology 78: 4552-4560.
Barton LM, Duval EJ, Stroberg E, Ghosh S, Mukhopadhyay S (2020) Covid-19 autopsies, oklahoma, USA. American Journal of Clinical Pathology 153: 725-733.

Bellmeyer A, Martino JM, Chandel NS, Scott Budinger GR, Dean DA, Mutlu GM (2007) Leptin resistance protects mice from hyperoxia-induced acute lung injury. American Journal of Respiratory and Critical Care Medicine 175: 587-594.

Bojkova D, Klann K, Koch B, Widera M, Krause D, Ciesek S, Münch C (2020) SARS-CoV-2 infected host cell proteomics reveal potential therapy targets. Nature Research DOI: 10.21203/rs.3.rs$17218 / v 1$

Buchholz UJ, Bukreyev A, Yang L, Lamirande EW, Murphy BR, Subbarao K, Collins PL (2004) Contributions of the structural proteins of severe acute respiratory syndrome coronavirus to protective immunity. Proceedings of the National Academy of Sciences 101: 9804-9809.

Cao B, Wang Y, Wen D, Liu W, Wang J, Fan G, Li X (2020a) A trial of lopinavir-ritonavir in adults hospitalized with severe COVID-19. New England Journal of Medicine382:1787-1799.

Cao Y, Li L, Feng Z, Wan S, Huang P, Sun X, Wang W (2020b) Comparative genetic analysis of the novel coronavirus (2019nCoV/SARS-CoV-2) receptor ACE2 in different populations. Cell discovery $6: 1-4$.

Chen G, Wu D, Guo W, Cao Y, Huang D, Wang H, Zhang X, et al. (2020) Clinical and immunologic features in severe and moderate forms of Coronavirus Disease. Journal of Clinical Investigation 137244. DOI: $10.1172 / \mathrm{JCI} 137244$

Chiu SS, Hung Chan K, Wing Chu K, Kwan SW, Guan Y, Man Poon LL, Peiris JSM (2005) Human coronavirus NL63 infection and other coronavirus infections in children hospitalized with acute respiratory disease in Hong Kong, China. Clinical infectious diseases 40: 1721-1729.

Dhama K, Patel SK, Pathak M, Yatoo MI, Tiwari R, Malik YS, Rodriguez-Morales AJ (2020a) An update on SARS-CoV2/COVID-19 with particular reference to its clinical pathology, pathogenesis, immunopathology and mitigation strategies. Travel Medicine and Infectious Disease 101755.

Dhama K, Sharun K, Tiwari R, Dadar M, Malik YS, Singh KP, Chaicumpa W (2020b) COVID-19, an emerging coronavirus infection: advances and prospects in designing and developing vaccines, immunotherapeutics, and therapeutics. Human vaccines \& Immunotherapeutics 1-7.

Gaur P, Saini S, Vats P, Kumar B (2018) Regulation, signalling and functions of hormonal peptides in pulmonary vascular remodelling during hypoxia. Endocrine 59: 466-480. 
Gupte M, Thatcher SE, Boustany-Kari CM, Shoemaker R, Yiannikouris F, Zhang X, Cassis LA (2012) Angiotensin converting enzyme 2 contributes to sex differences in the development of obesity hypertension in C57BL/6 mice. Arteriosclerosis, thrombosis, and vascular biology 32: 1392-1399.

Hamming I, Timens W, Bulthuis MLC, Lely AT, Navis GV, van Goor H (2004) Tissue distribution of ACE2 protein, the functional receptor for SARS coronavirus. A first step in understanding SARS pathogenesis. The Journal of Pathology: A Journal of the Pathological Society of Great Britain and Ireland 203: 631-637.

He L, Ding Y, Zhang Q, Che X, He Y, Shen H, Deng Y (2006) Expression of elevated levels of pro- inflammatory cytokines in SARS- CoV- infected ACE2+ cells in SARS patients: relation to the acute lung injury and pathogenesis of SARS. The Journal of Pathology: A Journal of the Pathological Society of Great Britain and Ireland 210: 288-297.

Hoffmann M, Kleine-Weber H, Krüger N, Mueller MA, Drosten C, Pöhlmann S (2020a) The novel coronavirus 2019 (2019-nCoV) uses the SARS-coronavirus receptor ACE2 and the cellular protease TMPRSS2 for entry into target cells. BioRxiv doi: https://doi.org/10.1101/2020.01.31.929042.

Hoffmann M, Kleine-Weber H, Schroeder S, Krüger N, Herrler T, Erichsen S, Müller MA (2020b) SARS-CoV-2 cell entry depends on ACE2 and TMPRSS2 and is blocked by a clinically proven protease inhibitor. Cell 181: 271-280.

Hui DS, Azhar EI, Madani TA, Ntoumi F, Kock R, Dar O, Zumla A (2020) The continuing 2019-nCoV epidemic threat of novel coronaviruses to global health-The latest 2019 novel coronavirus outbreak in Wuhan, China. International Journal of Infectious Diseases 91: 264-266.

Hussain M, Jabeen N, Raza F, Shabbir S, Baig AA, Amanullah A, Aziz B (2020) Structural variations in human ACE2 may influence its binding with SARS- CoV- 2 spike protein. Journal of Medical Virology 92:1580-1586.

Ibrahim HS, Froemming GRA, Omar E, Singh HJ (2014) ACE2 activation by xanthenone prevents leptin-induced increases in blood pressure and proteinuria during pregnancy in SpragueDawley rats. Reproductive Toxicology 49: 155-161.

Ingallinella P, Bianchi E, Finotto M, Cantoni G, Eckert DM, Supekar VM, Pessi A (2004) Structural characterization of the fusion-active complex of severe acute respiratory syndrome (SARS) coronavirus. Proceedings of the National Academy of Sciences 101: 8709-8714.

Janson G, Zhang C, Prado MG, Paiardini A (2017) PyMod 2.0: improvements in protein sequence-structure analysis and homology modeling within PyMOL. Bioinformatics 33: 444-446.
Jayawardena N, Burga LN, Poirier JT, Bostina M (2019) Virusreceptor interactions: Structural insights for oncolytic virus development. Oncolytic Virotherapy 8: 39.

Jordan RE, Adab P, Cheng KK (2020) COVID-19: risk factors for severe disease and death.BMJ 368:m1198

Kanne JP (2020) Chest CT findings in 2019 novel coronavirus (2019-nCoV) infections from Wuhan, China: key points for the radiologist. Radiology 295: 16-17.

Keam S, Megawati D, Patel SK, Tiwari R, Dhama K, Harapan H (2020) Immunopathology and immunotherapeutic strategies in severe acute respiratory syndrome coronavirus 2 infection. Reviews in Medical Virology 30: e2123.

Klok FA, Kruip MJHA, Van Der Meer NJM, Arbous MS, Gommers DAMPJ, Kant KM, Endeman H (2020) Confirmation of the high cumulative incidence of thrombotic complications in critically ill ICU patients with COVID-19: an updated analysis. Thrombosis Research 191:148-150.

Kuba K, Imai Y, Rao S, Gao H, Guo F, Guan B, Bao L (2005) A crucial role of angiotensin converting enzyme 2 (ACE2) in SARS coronavirus-induced lung injury. Nature Medicine 11: 875-879.

Lai CC, Shih TP, Ko WC, Tang HJ, Hsueh PR (2020) Severe acute respiratory syndrome coronavirus 2 (SARS-CoV-2) and coronavirus disease-2019 (COVID-19): the epidemic and the challenges. International Journal of Antimicrobial Agents 55(3):105924. doi: 10.1016/j.ijantimicag.2020.105924.

Letko M, Munster V (2020) Functional assessment of cell entry and receptor usage for lineage B $\beta$-coronaviruses, including 2019nCoV. BioRxiv doi: https://doi.org/10.1101/2020.01.22.915660.

Li W, Moore MJ, Vasilieva N, Sui J, Wong SK, Berne MA, Choe $\mathrm{H}$ (2003) Angiotensin-converting enzyme 2 is a functional receptor for the SARS coronavirus. Nature 426: 450-454.

Li W, Sui J, Huang IC, Kuhn JH, Radoshitzky SR, Marasco WA, Farzan M (2007) The S proteins of human coronavirus NL63 and severe acute respiratory syndrome coronavirus bind overlapping regions of ACE2. Virology 367: 367-374.

Liu S, Xiao G, Chen Y, He Y, Niu J, Escalante CR, Jiang S (2004) Interaction between heptad repeat 1 and 2 regions in the spike protein of SARS-associated coronavirus: implications for virus fusogenic mechanism and identification of fusion inhibitors. The Lancet 363: 938-947.

Liu MY, Zheng B, Zhang Y, Li JP (2020) Role and mechanism of angiotensin-converting enzyme 2 in acute lung injury in 
coronavirus disease 2019. Chronic Diseases and Translational Medicine 6(2):98-105. DOI: 10.1016/j.cdtm.2020.05.003.

Luytjes W, Sturman LS, Bredenbee PJ, Charite J, van der Zeijst BA, Horzinek MC, Spaan WJ (1987) Primary structure of the glycoprotein E2 of coronavirus MHV-A59 and identification of the trypsin cleavage site. Virology 161: 479-487.

MacIntyre CR (2020) Wuhan novel coronavirus 2019ncov-update January 27th, 2020. Global Biosecurity 1: 3.

Malik YS, Kumar N, Sircar S, Kaushik R, Bhat S, Dhama K, Zowalaty MEE (2020) Coronavirus disease pandemic (COVID19): challenges and a global perspective. Pathogens 9: 519.

Marra MA, Jones SJ, Astell CR, Holt RA, Brooks-Wilson A, Butterfield YS, Cloutier A (2003) The genome sequence of the SARS-associated coronavirus. Science 300: 1399-1404.

Matoba Y, Abiko C, Ikeda T, Aoki Y, Suzuki Y, Yahagi K, Mizuta K (2015) Detection of the human coronavirus 229E, HKU1, NL63, and OC43 between 2010 and 2013 in Yamagata, Japan. Japanese Journal of Infectious Diseases 68: 138-141.

Miller SE, Brealey JK (2020) Visualization of putative coronavirus in kidney. Kidney International 98: 231-32.

Monteil V, Kwon H, Prado P, Hagelkrüys A, Wimmer RA, Stah M, Romero JP (2020) Inhibition of SARS-CoV-2 infections in engineered human tissues using clinical-grade soluble human ACE2. Cell 181:905-913.

O'Keeffe S (2019) Aspiration pneumonia. New England Journal of Medicine 380: E40.

Penn BH, Netter Z, Johnson JR, Von Dollen J, Jang GM, Johnson T, Golovkine G (2018) An Mtb-human protein-protein interaction map identifies a switch between host antiviral and antibacterial responses. Molecular Cell 71: 637-648.

Pyrc K, Jebbink MF, Berkhout B, Van der Hoek L (2004) Genome structure and transcriptional regulation of human coronavirus NL63. Virology Journal 1: 7.

Qamar SA, Basharat K, Bilal M, Iqbal HMN (2020) Therapeutic Modalities for SARS-CoV-2 (COVID-19): Current Status and Role of Protease Inhibitors to Block Viral Entry into Host Cells Journal of Pure and Applied Microbiology 14: 1695-1703.

Ramaiah A, Koralur MC, Dasch GA (2018) Complexity of typespecific $56 \mathrm{kDa}$ antigen CD4 T-cell epitopes of Orientia tsutsugamushi strains causing scrub typhus in India. PLoS One 13: e0196240.
Ranucci M, Ballotta A, Di Dedda U, Bayshnikova E, Dei Poli M, Resta M, Menicanti L (2020) The procoagulant pattern of patients with COVID- 19 acute respiratory distress syndrome. Journal of Thrombosis and Haemostasis 18:1747-1751.

Sanchis-Gomar F, Lavie CJ, Perez-Quilis C, Henry BM, Lippi G (2020) Angiotensin-Converting Enzyme 2 and antihypertensives (angiotensin receptor blockers and angiotensin-converting enzyme inhibitors) in Coronavirus Disease 2019. Mayo Clinic Proceedings 95(6): 1222-1230.

Sawalha AH, Zhao M, Coit P, Lu Q (2020) Epigenetic dysregulation of ACE2 and interferon-regulated genes might suggest increased COVID-19 susceptibility and severity in lupus patients. Clinical Immunology 108410. doi: 10.1016/j.clim.2020.108410.

Sievers F, Wilm A, Dineen D, Gibson TJ, Karplus K, Li W, Thompson JD (2011) Fast, scalable generation of high- quality protein multiple sequence alignments using Clustal Omega. Molecular Systems Biology 7: 539. doi: 10.1038/msb.2011.75.

Takahashi Y, Haga S, Ishizaka Y, Mimori A (2010) Autoantibodies to angiotensin-converting enzyme 2 in patients with connective tissue diseases. Arthritis Research \& Therapy 12: 1-8.

Tian S, Xiong Y, Liu H, Niu L, Guo J, Liao M, Xiao SY (2020) Pathological study of the 2019 novel coronavirus disease (COVID19) through postmortem core biopsies. Modern Pathology 33: $1007-1014$

Van Der Hoek L, Pyrc K, Berkhout B (2006) Human coronavirus NL63, a new respiratory virus. FEMS microbiology reviews 30: 760-773.

van der Voort P, Moser J, Zandstra DF, Kobold ACM, Knoester M, Calkhoven CF, van Meurs M (2020) A clinical and biological framework on the role of visceral fat tissue and leptin in SARSCoV-2 infection related respiratory failure. medRxiv.

Varga Z, Flammer AJ, Steiger P, Haberecker M, Andermatt R, Zinkernagel AS, Moch H (2020) Endothelial cell infection and endotheliitis in COVID-19. The Lancet 395: 1417-1418.

Wang D, Hu B, Hu C, Zhu F, Liu X, Zhang J, Zhao Y (2020a) Clinical characteristics of 138 hospitalized patients with 2019 novel coronavirus-infected pneumonia in Wuhan, China. Jama 323: 1061-1069.

Wang L, Wang Y, Ye D, Liu Q (2020b) A review of the 2019 Novel Coronavirus (COVID-19) based on current evidence. International Journal of Antimicrobial Agents 55(6):105948. DOI: https://doi.org/10.1016/j.ijantimicag.2020.105948. 
Wang P, Chen J, Zheng A, Nie Y, Shi X, Wang W, Song X (2004) Expression cloning of functional receptor used by SARS coronavirus. Biochemical and Biophysical Research Communications 315: 439-444.

Wong SK, Li W, Moore MJ, Choe H, Farzan M (2004) A 193amino acid fragment of the SARS coronavirus $\mathrm{S}$ protein efficiently binds angiotensin-converting enzyme 2. Journal of Biological Chemistry 279: 3197-3201.

World Health Organization, \& World Health Organization. (2020). Report of the WHO-China joint mission on coronavirus disease 2019 (COVID-19).

Wu F, Zhao S, Yu B, Chen YM, Wang W, Song ZG, Yuan ML (2020) A new coronavirus associated with human respiratory disease in China. Nature 57: 265-269.

Xiao X, Chakraborti S, Dimitrov AS, Gramatikoff K, Dimitrov DS (2003) The SARS-CoV S glycoprotein: expression and functional characterization. Biochemical and biophysical research communications 312: 1159-1164.

Xu H, Zhong L, Deng J, Peng J, Dan H, Zeng X, Chen Q (2020a) High expression of ACE2 receptor of 2019-nCoV on the epithelial cells of oral mucosa. International Journal of Oral Science 12: 1-5.

Xu Z, Shi L, Wang Y, Zhang J, Huang L, Zhang C, Tai Y (2020b) Pathological findings of COVID-19 associated with acute respiratory distress syndrome. The Lancet respiratory medicine 8: 420-422.

Zhang H, Zhou P, Wei Y, Yue H, Wang Y, Hu M, Guo G (2020) Histopathologic changes and SARS-CoV-2 immunostaining in the lung of a patient with COVID-19. Annals of Internal Medicine 172: 629-632.

Zhang YH, Zhang YH, Dong XF, Hao QQ, Zhou XM, Yu QT, Zhang Y (2015) ACE2 and Ang-(1-7) protect endothelial cell function and prevent early atherosclerosis by inhibiting inflammatory response. Inflammation Research 64: 253-260. 